\title{
FUNDAMENTOS JURÍDICOS DEL DERECHO AL OLVIDO. ¿UN NUEVO DERECHO DE ORIGEN EUROPEO O UNA RESPUESTA TIIPICA ANTE COLISIONES ENTRE CIERTOS DERECHOS FUNDAMENTALES?
}

\author{
LEGAL BASIS OF THE RIGHT TO BE FORGOTTEN.A NEW RIGHT \\ FROM EUROPE OR A TYPICAL RESPONSE FOR COLLISIONS \\ BETWEEN CERTAIN FUNDAMENTAL RIGHTS?
}

\author{
Francisco J. LetUria I. ${ }^{*}$
}

\begin{abstract}
RESUMEN: Durante los últimos años, especialmente en el contexto europeo, se ha planteado la posibilidad de dar reconocimiento positivo al derecho al olvido. Este derecho favorecería la capacidad de cada persona de desarrollar libremente su propia vida, sin la interferencia de hechos de su propio pasado, que bajo el actual estatuto de la libertad de expresión, podrían ser difundidos sin ninguna limitación temporal. Postulamos que más allá de la novedad y utilidad de esta posible explicitación normativa, este derecho ha sido crecientemente reconocido en las últimas décadas, bajo diferentes fórmulas y argumentaciones.
\end{abstract}

Palabras clave: Derecho al olvido, libertad de expresión, protección de datos, ponderación, derechos fundamentales, interpretación constitucional, privacidad, presunción de inocencia, debido proceso, publicidad judicial, rehabilitación del delincuente.

ABSTRACT: During recent years, the possible recognition of a new fundamental right has increasingly gained acceptance, especially within the European context. It is the right to forget and it favors the capacity of each person to freely develop their own life, without the interference of events from their past life. Under the current statute of the freedom of expression it could be possible to defend this new right without temporal limitations. Nevertheless, this right exists and it has been increasingly recognized in recent decades as a result of its weighing against other fundamental rights and the growing understanding of privacy as autonomy. However, its positivisation could also bring about important benefits.

Key words: Right to forget, freedom of expression, data protection, weighing, fundamental rights, constitutional interpretation, privacy, presumption of innocence, due process, judicial advertising, rehabilitation of the offender.

\section{INTRODUCCIÓN}

La proliferación de mecanismos de registro y conservación de datos y el acceso facilitado ofrecido por las nuevas tecnologías, ha puesto sobre el tapete la posibilidad de controlar y limitar la divulgación de informaciones que puedan condicionar negativamente el libre accionar de una persona.

\footnotetext{
* Abogado y Doctor en Derecho por la Universidad de Salamanca. Profesor de la Facultad de Derecho de la Pontificia Universidad Católica de Chile y Presidente del Centro Nacional de Arbitrajes. Dirección postal: Alameda 340 piso 4 (Facultad de Derecho UC), Santiago de Chile. Dirección electrónica: fjleturia@uc.cl.
} 
El derecho al olvido ha cobrado especial interés por la incorporación expresa del mismo en la Propuesta de Reglamento General de Protección de Datos Personales de la Comisión Europea ${ }^{1}$, y del "caso Google", fallado el 13 de mayo de 2014 por el Tribunal de Justicia de la Unión Europea (TJUE) ${ }^{2}$.

Sostendremos en este trabajo que este derecho no es nuevo, sino que ha estado presente de diversas maneras en la jurisprudencia y doctrina comparada. El derecho al olvido sería solo una fórmula más clara y didáctica para legitimar restricciones a la libertad de expresión e información en beneficio de otros derechos (honra, intimidad, privacidad, derecho a la resocialización, protección de la autonomía personal, protección de las normas de un juicio justo, entre otras), que surge como respuesta natural a una situación de conflicto entre dos pretensiones incompatibles. En todas estas situaciones, el elemento "temporal" es central, distinguiéndolo de otros ejercicios de ponderación que también imponen límites o contornos específicos a la libertad de expresión ${ }^{3}$.

Las situaciones clásicas vinculadas a su desarrollo en general han podido ser resueltas en forma razonablemente satisfactoria en base a las disposiciones legales tradicionales y al reconocimiento de principios y derechos fundamentales. No obstante, es posible que en la actualidad una explicitación del mismo facilite la labor judicial y el logro de los objetivos buscados, siguiendo una tendencia especificadora que es posible ver también en muchos otros derechos, donde su positivización reconoce una realidad jurídica ya ampliamente aceptada, pero no por ello su mención, lejos de ser redundante, acarrea una serie de beneficios operativos: permite reducir y ordenar el debate, establecer criterios claros y objetivos, realzar ciertos objetos de protección, confirmar los supuestos en el tipo de lógica en que el sistema de derechos debe ser interpretado, explicitar su contenido y operatividad, entre otras ${ }^{4}$.

En el caso particular de los datos personales y el mundo digital, parece haber buenas razones prácticas y prudenciales para promover una reglamentación clara, específica y general 5 . No obstante, al reglamentar dichos ámbitos es común que se incluyan dentro del "derecho al olvido" situaciones que buscan la protección de bienes jurídicos y situaciones diferentes, y que quedan cubiertas con solicitudes de rectificación o borrado de datos. Dada su extensión, dejaremos la problemática propia del mundo de internet para un próximo trabajo.

\footnotetext{
${ }^{1}$ Reglamento General de Protección de Datos Personales de la Comisión Europea (2012b) artículo 17. Sin embargo, en este reglamento se identifica este derecho básicamente con la cancelación de datos personales en internet, dejando excluidas otras versiones más clásicas como la vinculada a la resocialización de los condenados en materia penal, o la protección de la privacidad en general, tal como analizaremos en las páginas que siguen. Cabe señalar que en la versión de la propuesta, aprobada el 21 de octubre de 2013 por el Parlamento Europeo, se eliminó la expresión derecho al olvido manteniendo el borrado de datos y el resto del artículo básicamente idéntico. A nivel doctrinario, también se habla de un nuevo derecho fundamental. Por ejemplo, OrzA (2012), en sus conclusiones.

2 Sentencia del Tribunal Europeo de Justicia (TJUE) de 13 de mayo de 2014, dictado por la gran sala y recaída (asunto C131/12, planteado por la Audiencia Nacional, mediante auto de 27 de febrero de 2012, en el procedimiento entre Google Spain, S.L., Google Inc. y Agencia Española de Protección de Datos (AEPD), Mario Costeja González. El caso es desarrollado más adelante.

3 Palermo (2010) p. 279.

4 Rolla (2002) pp. 139-167.

5 OrZa (2012) en sus conclusiones.
} 


\section{CIRCUNSTANCIAS HISTÓRICAS QUE HAN ACOMPAÑADO EL RECIENTE DESARROLLO DEL DERECHO AL OLVIDO}

Pocas situaciones jurídicas muestran mejor la dimensión histórica del derecho como el derecho al olvido.

Producto de ello, el derecho al olvido presenta alcances y dinámicas muy diferentes según el país y la tradición jurídica que se observe. La comprensión de la libertad de expresión y del derecho a la privacidad en EE.UU. y en Europa, por ejemplo, difiere lo suficiente como para augurar un mayor desarrollo del derecho al olvido en los países del viejo continente $^{6}$, lo que dará espacio para tensiones y conflictos permanentes, como los ya observados en el caso Google.

Francia quizá sea el país donde la protección de la privacidad frente a la libertad de expresión alcanza su mayor intensidad, habiendo aceptado la consideración al elemento temporal como relevante en la protección de la privacidad en numerosas oportunidades. Así, por ejemplo, frente al reclamo presentado por una ex amante del asesino en serie Henri Landru relativa a su mención en una película, se aceptó la alegación de que ello correspondía a un periodo muy antiguo y dramático de su vida privada y que quería dejar atrás ${ }^{7}$. El mismo criterio se utilizó frente a la publicación de la autobiografía de un famoso delincuente (Mesrine), frente al reclamo de una ex pareja que alegaba que el texto perjudicaba la reinserción social que había logrado ${ }^{8}$. El retirado cantante Jean Ferrat, recibió protección judicial luego de protestar por la revelación, por medio de la prensa, de su nombre y domicilio?.

Un caso aún más interesante se originó por la inclusión, en un juego de mesa tipo "trivia", de una pregunta sobre el nombre del médico que en su juventud había sido sorprendido robando un banco. La justicia acogió la petición de prohibición de venta y retiro del juego, rechazando el argumento de que los hechos ya publicados o los asuntos judiciales fueran por sí mismos noticiables en forma indefinida, agregando que el tiempo transcurrido había quitado el interés público a los hechos, por lo que ya no existía una necesidad social de contar con información sobre ellos ${ }^{10}$.

En 2004, siguiendo el mismo criterio, el Tribunal de Casación revocó una sentencia que sostenía que la publicación, en una película, de hechos relativos a un accidente familiar afectaba la vida y la personalidad del reclamante ${ }^{11}$. En otro caso, la Corte de Casación, pese a que rechazó dar protección solicitada por una mujer mencionada en un libro como compañera de un colaboracionista, señaló como criterios de legitimidad que las publicaciones originales (en caso que las hubiera) hubiesen sido realizadas al amparo de la ley, y que persistiera un interés actual que justificara publicación ${ }^{12}$.

\footnotetext{
6 Rosen (2012), Werro (2009) pp. 285-300 y Bennett (2012) pp. 161-195.

7 Sentencia del Tribunal de Gran Instancia de Sena, 4 de octubre de 1965.

8 Sentencia del Tribunal de Gran Instancia de París, 6 de diciembre de 1979.

9 Sentencia de la Corte de Apelaciones de París, 15 de mayo de 1970.

10 Sentencia del Tribunal de Gran Instancia de París, Sala Primera, 25 de marzo de 1987.

11 Sentencia de la Corte de Casación, Sala Civil 2, de 3 de junio de 2004.

12 Sentencia de la Corte de Casación Civil del 20 de noviembre de 1990. Pueden encontrarse referencia a estos casos y a otros en Mezzanotte (2009) pp. 216 y ss.
} 
En Italia, el derecho al olvido era ya mencionado en una sentencia de $1958^{13}$. Cuatro décadas más tarde, se reconocía en forma expresa, refiriéndose al "justo interés de cada individuo de no estar indefinidamente expuesto a datos que afectan negativamente su honor o reputación, relativa a la reiterada publicación de una noticia divulgada en el pasado" ${ }^{14}$.

Estos ejemplos muestran la forma general de la tradición continental europea respecto de esta situación ${ }^{15}$. En EE.UU., por el contrario, la amplia protección dada a la difusión libre de información y la concepción de la privacidad en su forma más restrictiva y vinculada al derecho de propiedad, hace más difícil cualquier restricción a la primera enmienda ${ }^{16}$. Dada la enorme influencia del derecho americano en el mundo, y en particular, en el desarrollo de la libertad de expresión, nos detendremos brevemente en dichos criterios.

La solución dominante en el sistema americano parece ser la adoptada en el caso Brisco v. Reader's Digest Association, Inc., donde se consideró legítima la publicidad dada al autor de un delito cometido 11 años atrás a propósito de un nuevo ilícito, dada la prevalencia del interés de la noticia sobre los demás derechos afectados ${ }^{17}$. Un criterio similar se utilizó en el caso Jenkinsv. Dell Publishing Co., donde la familia de una víctima de asesinato autorizó y facilitó la cobertura periodística del mismo, pero luego protestó ante la inclusión del material en un libro de crímenes. El Tribunal Supremo Federal (TSA) señaló que una vez que un asunto era noticia, no resulta factible ni deseable para un tribunal comenzara a distinguir entre noticias que buscaban informar y aquellas que buscaban entretener ${ }^{18}$.

Un caso levemente diferente afectó a William J. Sidis, conocido desde niño por sus asombrosas facultades intelectuales, pero que con el correr del tiempo, desarrolló una vida discreta. En 1937 el New Yorker publicó un artículo sobre su vida adulta, dando origen a un reclamo por invasión a la privacidad. El Tribunal de Apelaciones de Nueva York rechazó la solicitud señalando que "lamentablemente o no, las desgracias y debilidades de los vecinos y "figuras públicas "son temas de gran interés y debate con el resto de la población"19,

\footnotetext{
13 Sentencia de la Corte de Casación del 13 mayo de 1958, № 1563, conocida como el caso Caruso. Ver también Mezzanotte (2009) pp. 82 y 98 (cita 67).

14 Sentencia de la Corte de Casación de 9 abril de 1998, No 3679. Más recientemente, vemos sentencias que manifiestan "una voluntad orientada al reconocimiento de un derecho, cuyos contornos son todavía poco claros”. Mezzanotte (2009) p. 277 (haciendo expresa referencia a la sentencia No 45051 de 24 de noviembre del 2009, dictada por la sección quinta de la Corte de Casación Penal italiana).

15 En España, por ejemplo, la STC 52/2002, estimó que la publicidad mediática dada a los antecedentes penales de una persona por una violación acaecida hace doce años, y por un arresto menor, eran superfluas e innecesarias, dado que la noticia fundamental se había centrado en descartar su participación en el doble crimen (homicidio). Añadir aquellas referencias, que afectan a su probidad, reputación y dignidad personal, era innecesario, al "no poder calificarse de veraz y carecer de relevancia e interés público". (FJ 7 y FJ 8). En Alemania, por ejemplo, el llamado caso Lebach (BVerfGE 35, 2002, 1973).

16 Werro señala que en EE.UU. "el desarrollo de un derecho a ser olvidado (...) no viene, como en Europa, derivado de un equilibrio entre los derechos reconocidos en la Constitución, sino más bien, de una serie de intentos por parte de los diversos estados de forjar para sus ciudadanos una esfera de la intimidad inviolable respecto de los medios de comunicación (...)”. Werro (2009) p. 292.

17 Briscoe v. Reader's Digest Association, Inc., 4 Cal.3d 529.

18 Jenkins v. Dell Publishing Co., 251F.2d447 (3d Circ.) (1958).

19 Sidis v. F-R Publishing Corp.,113 F.2d 806 (2d Cir.).
} 
ampliando, de paso, el concepto de figura pública a ámbitos que iban más allá de la vida política $^{20}$.

Luego, el criterio de máxima publicidad parece haberse consolidado en el caso Cox Broadcasting ${ }^{21}$, que declaró inconstitucional una ley de Georgia que prohibía la publicidad mediática de los nombres de las víctimas de violación.

Sin embargo, también se han presentado soluciones minoritarias en sentido contrario. Una de ellas, por ejemplo, favoreció a una dueña de casa de un pueblo del interior de los EE.UU., que fue sindicada por la prensa como principal sospechosa de un homicidio del que finalmente salió libre de cargos. Durante ese proceso, se difundió que durante su juventud la sospechosa había sido trabajadora sexual, hecho del todo desconocido de su familia y su comunidad, generándole perjuicios de todo tipo, entre los que cabe imaginar un aumento de las sospechas de culpabilidad por parte de la opinión pública, y probablemente del jurado. Pocos años después, su caso fue llevado al cine, donde incluso se utilizó el nombre de soltera de la afectada. Frente a las reclamaciones de la afectada, el TS-California consideró que si bien los datos eran públicos y reales, cualquier persona que hubiera rehecho su vida tenía derecho a la búsqueda de la felicidad y a no sufrir ataques innecesarios, y que el uso de su nombre verdadero no aportaba información para ilustrar el caso ${ }^{22}$.

Más recientemente, el caso US Dept. of Justice v. Reporters Committe ${ }^{23}$ se refirió a la "Freedom of Information Act" (FOIA), que permite obtener acceso a las informaciones de las instituciones públicas. El caso se originó por la negativa dada por el Departamento de Justicia de entregar a un grupo de periodistas informaciones recopiladas por el FBI respecto a un caso de corrupción. El FBI entregó información sobre los involucrados que habían fallecido, pero señaló que respecto del sobreviviente solo entregaría información si hubiera un interés público relativo a delitos financieros (cosa que no ocurría) y no sobre otras materias. El TSA validó el criterio, señalando la privacidad estaba protegida por la excepción 7 c) de la FOIA (vinculada al factor temporal), agregando que el propósito de esta normativa era permitir el público escrutinio público de los actos de gobierno, y no el obtener información privada de otros ciudadanos. Por ello, aunque el registro no era "privado", podían justificarse la protección de intereses individuales que buscaran limitar su publicidad ${ }^{24}$.

Un caso aún más interesante se originó en la sentencia que cuestionó la legitimidad de una publicación que hacía referencia a actividades homosexuales entre adultos y adolescentes acontecidos a mitad de los años 50, generando gran revuelo (una de las personas involucradas fue luego expulsada de la Academia de West Point). La sentencia consideró que el caso era muy distinto al precedente de Cox Broadcasting $g^{25}$ y de toda la jurisprudencia na-

\footnotetext{
20 Covarrubias (2005) p. 169.

21 Cox Broadcasting Corp. v. Cohn, 420 U.S. 469 (1975). Florida Star v. B. J. F., 491 U.S. 524 (1989).

22 Melvin v. Reid, 112 Cal. App. 285, 297 P. 91 (1931). En este caso la Corte no pudo referirse expresamente a la privacidad porque no fue invocado por las partes.

23 US Dept. of Justice v. Reporters Committee, 489 U.S. 749 (1989).

24 Estas directrices no son seguidas en la práctica. Massimiliano Mezzanotte, "Il Diritto All'oblio. Contributo Allo Studio Della Privacy Storica”, ed. Collana della Facoltá di Giurisprudenza, Universita degli studi di Teramo, Edizioni Scientifiche Italiane (2009), pp. 241-242.

25 Cox Broadcasting Corp. v. Cohn, 420 U.S. 469 (1975).
} 
cida a su amparo, señalando que en algunos casos el interés público era dudoso ${ }^{26}$. Dado el giro que esta sentencia podía implicar frente a la tradicional comprensión de la primera enmienda, fue objeto de un recurso especial ante el Tribunal Supremo de Idaho ("rehearing"), la que validó tanto la publicación como los criterios de las instancias inferiores, reiterando las dudas sobre cómo el paso del tiempo podría afectar el interés público de un hecho, así como la dificultad de determinarlo ${ }^{27}$.

Después de la Segunda Guerra Mundial, los sistemas jurídicos europeos han visto una evolución centrada en la valorización de los derechos de la personalidad como los elementos estructurales del ordenamiento jurídico (muchos autores han llamado a este proceso "neoconstitucionalismo ${ }^{28}$ ). Lo anterior ha obligado a comprender las disposiciones legales de un modo más amplio, así como a considerar y balancear intereses contrapuestos, que en el caso que nos ocupa incluyen, por un lado, el derecho del individuo a vivir sin interferencias injustificadas que limiten sus derechos, su autonomía y sus posibilidades de desarrollo; y por otro, la resistencia que debe existir ante la demanda de limitar la libertad de expresión e información, atendido su rol fundamental en una sociedad democrática, especialmente notorio cuando se refiere a materias de interés público ${ }^{29}$.

En ese esquema, "memoria", "información” y "recuerdo" presentan una doble faz. Por un lado resultan fundamentales para el desarrollo individual y colectivo, pero al mismo tiempo puede también plantear aspectos negativos y provocar daños y restricciones a la vida social e individual de diverso tipo, perjudicando las posibilidades actuales por causa del pasado. Si el recuerdo de hechos pasados tuviera una cierta capacidad restrictiva, estigmatizante o limitadora para el desarrollo humano, la adopción de medidas que minimicen dichas consecuencias sería razonable, sin pretender afectar ni las comunicaciones estrictamente privadas ni el fuero interno.

\section{FUNDAMENTOS JURÍDICOS DEL DERECHO AL OLVIDO}

Para efectos de este trabajo, definiremos el derecho al olvido como el fundamento jurídico que permite que ciertas informaciones del pasado no sean actualmente difundidas cuando son capaces de provocar más daños que beneficios ${ }^{30}$.

Ello es consecuencia de un juicio de valor que considera que, atendidas determinadas circunstancias, el beneficio del ejercicio de la libertad de expresión es inferior a los daños provocados en otros bienes jurídicos.

\footnotetext{
26 Uranga v. Federal Publication Inc, Idaho, Supreme Court (21 de junio de 2001).

$27{ }^{56}$ Uranga v. Federal Publication Inc, Idaho, Supreme Court No 27118 (14 de febrero de 2003). La corte señaló, respecto de la publicidad del nombre, que cada elemento de la noticia era relevante.

${ }^{28}$ A modo de ejemplo, ver Aldunate (2010) pp. 79-102; Bernal (2007) pp. 289-326; Comanducci (2002) pp. 89-112; Fioravanti (1996) pp. 127-134; Guastini (2010); Pozzollo(1998) pp. 339-353; y Prieto SanCHIS (2003).

${ }^{29}$ Cabe recordar que este paradigma también significó el cambio de lógica frente a los actos de gobierno, desde las históricas prácticas de opacidad y secreto hacia un criterio de máxima publicidad, con el objeto de favorecer el escrutinio público de los mismos, y el debate y participación democrática.

${ }^{30} \mathrm{La}$ expresión inglesa para este derecho es "the right to be forgotten", lo que puede llevar a equívocos en este sentido, pues no consiste en un derecho a ser olvidado. A modo de ejemplo, ver el trabajo de FLEISHER (2012).
} 
En un sentido similar, Palermo define el derecho al olvido como "el justo interés de cada persona de no quedar expuesto en forma indeterminada al daño que impone a su honor y a su reputación la reiterada publicación de una noticia legítimamente divulgada en el pasado" 31 . Por tanto, precisa, el elemento constitutivo de este derecho consiste en que hechos que fueron o pudieron ser públicos, dado el transcurso del tiempo, vuelven al área de la privacidad o reserva. Este elemento temporal no está presente en la comprensión clásica de la privacidad, aunque hay autores que ya comienzan a referirse a una "privacidad histórica"32.

En los últimos años, la relevancia de los asuntos vinculados a la protección de datos personales ha llevado a identificar el derecho al olvido con esta manifestación específica del mismo ${ }^{33}$, o con situaciones que sin parecerse, admiten una solución similar (como por ejemplo la posibilidad de solicitar la eliminación de cierta información disponible en internet por ser de carácter confidencial o íntima).

Más allá de las crecientes propuestas normativas asociadas a la necesidad de regular el uso de datos personales, sostendremos que el derecho al olvido puede y debe ser analizado desde a la lógica de los derechos fundamentales, y más concretamente, desde la lógica de los conflictos de derechos ${ }^{34}$, que adopta esta forma didáctica para justificar cierto reforzamiento de la privacidad y de otros derechos ${ }^{35}$, o lo que es lo mismo, establecer límites a la libertad de expresión.

Incluso en los casos en que este derecho al olvido pueda alcanzar reconocimiento normativo (a nombre propio o de otros equivalentes como "derecho al borrado de datos, rectificación u otros), ello debe entenderse como un ejercicio de ponderación, realizado en sede legislativa, con el objeto de aumentar la certeza jurídica y facilitar el trabajo judicial.

31 Palermo (2010) p. 279. Costaz señala que el derecho al olvido tiene por objeto "asegurar la protección del pasado de un sujeto permitiéndole oponerse a la exhumación de hechos que pertenecen a un episodio de su vida que el tiempo ha vuelto secreto”. Costaz (1995) p. 963. Rolla entiende el derecho al olvido a la legítima pretensión de un individuo de no ver evocados hechos que forman parte de su experiencia pasada, sin interés público actual. Rolla (2002) p. 165.

32 Ello puede verse en el título de la obra de Mezzanote citada a lo largo de este trabajo: "Derecho al olvido: Una contribución al estudio de la Privacidad Histórica”. Mezzanotte (2009).

33 En parte esta confusión ha sido generada por la expresa mención que hace al derecho al olvido el Reglamento General de Protección de Datos Personales de la Comisión Europea (2012b), artículo 17, y el debate específico que ha generado. Fleisher (2012) señala que el "derecho a ser olvidado" abarca un amplio espectro de posibilidades y comprensiones en cuanto a su contenido. En un sentido más limitado, Orza sostiene que el derecho al olvido debería entenderse "como el derecho de las personas a impedir que datos personales propios circulen por internet sin su consentimiento". OrZA (2012), apartado 4.1. (la itálica es nuestra).Un caso diferente es el de ZÁraTe, que si bien define el derecho al olvido como "un derecho a no diseminar información personal pasada que, siendo inexacta o habiendo dejado de cumplir su finalidad, es capaz de producir un daño en la persona, que motiva el ejercicio de los derechos de cancelación, rectificación y oposición”, vinculándolo así a las formas de protección de que goza actualmente la protección de datos personales, luego se refiere al mismo utilizando un lenguaje propio de los derechos fundamentales autónomos y reconocidos jurídicamente, desarrollando el “contenido esencial del derecho al olvido". Zárate (2013) p. 9.

34 El punto 3.3 del Proyecto de Protección de Datos Personales de la Comunidad Europea señala que este derecho está estrechamente ligado "al respeto de la vida privada y familiar (...) y en particular del derecho a la intimidad”, en lo que respecta al tratamiento de datos personales. Rolla (2002) pp. 160-162.

35 ZÁrATE afirma que "el derecho al olvido no debe considerarse más allá de un término de fantasía para calificar un derecho a la cancelación, rectificación u oposición”. ZÁrate (2013) p. 3. Por su parte, Fleisher (2012) ha señalado que el derecho a ser olvidado es un "exitoso slogan político" que permite una pluralidad de contenidos. 
Esta aproximación al derecho al olvido nos traerá aparejadas una serie de ventajas, dado el abundante desarrollo que a nivel mundial observa este derecho, tanto a nivel jurisprudencial como doctrinario.

\section{La PRIVACIDAd COMO FUndamento DEL DERECHO AL OLVIDO}

Dado que existe consenso universal en que la privacidad y otros derechos pueden ser afectados, en distintos niveles o grados, por el interés superior existente en la libre publicación de informaciones y opiniones relativos a determinados hechos con relevancia social ${ }^{36}$, cualquier modificación del factor legitimador -el interés público informativo- alterará necesariamente los juicios de ponderación asociados, permitiendo, por ejemplo, una mayor protección de la honra y la privacidad por sobre el ejercicio informativo.

En EE.UU., la dificultad para definir estándares que permitan objetivar esta "pérdida de interés”, sumada a la comprensión del “interés público” como "interés del público", han llevado a sostener que una vez que un hecho se divulga, ingresa por siempre al flujo de información ${ }^{37}$.

Esta postura simplifica el trabajo jurisprudencial y refuerza la libertad de expresión, pero lo hace a costa de extender la protección a situaciones claramente dañosas y absurdas, y a una lógica contraria al sentido común y a la evidencia concreta que muestran cómo los hechos noticiosos pierden interés con el paso del tiempo ${ }^{38}$.

\footnotetext{
36 A modo de ejemplo, STC 52/2002, FJ 4. A nivel doctrinario, "La vida privada de las figuras públicas. El interés público como argumento que legitima la intromisión en la vida privada". COVARRUBIAS (2013).

37 El Tribunal Supremo Americano (TSA) ha señalado que no puede haber responsabilidad cuando la publicidad se basa en informaciones contenidas en registros públicos, ya que en esos casos la protección dada a la privacidad es de poco interés. Cox Broadcasting 494, 95 S.Ct. 1029; Jenkins v. Dell Publishing Co., 251 F.2d 447 (3d Circ.) (1958). Más recientemente, el mismo criterio se utilizó en Florida Star v. B. J. F., 491 U.S. 524 (1989). Asimismo, la jurisprudencia americana ha señalado que no hay indicios que permitan afirmar que la primera enmienda protege de diferente manera a los historiadores que a quienes reportean hechos actuales, ni que el ejercicio de esta libertad se ve afectada por el paso del tiempo. Bridges v. California, 314 U.S. 252, 62 S.Ct. 190, 86 L. Ed. 192 (1941). Frente a este aspecto particular ha señalado que ante la ausencia de criterios que permitan determinar cuándo una noticia era lo suficientemente vieja como para no recibir la protección de la primera enmienda, podía derivarse en situaciones de autocensura (derivados de la incertidumbre del informador frente a la legitimidad de sus actuaciones), que fue precisamente lo que quiso evitar la TS en Cox Publishing and The Florida Star (Uranga v. Federal Publication Inc, Idaho, Supreme Court No. 27118. (14 de febrero de 2003). Por lo mismo, debe confiarse en el criterio de quienes deciden publicar (Cox Broadcasting, 420 U.S. 496, 95 S.Ct. 1029). En el mismo sentido se manifiesta uno de los textos jurídicos más influyentes en la tradición jurídica norteamericana, el Restatement of Torts (Second), que señala que no habrá responsabilidad cuando se difundan hechos que ya son públicos. Restatement of Torts (Second), \$652D cmt. b (1976).

38 De hecho, el paso de los años normalmente hará disminuir, total o parcialmente, el interés público asociado a un hecho. La importancia de la pronta divulgación informativa de los asuntos de interés públicos es precisamente lo que justifica la tolerancia a cierto margen de error en las mismas por parte del comunicador. $\mathrm{Al}$ respecto, ver STC 6/1988, FJ 5; STC 28/1996, FJ 3; STC 2/2001, FJ 6; STC 158/2003, FJ 6; STC 160/2003, FJ 5; y STC 216/2006, FJ 8. En la jurisprudencia americana, puede consultarse Nueva York Times Co. v. Sullivan, 376 U.S. 254 (1964). En la Corte Europea de Derechos Humanos, la CEDH No 28525/95, Unabhängige Initiative Informationsvielfalt v. Austria, de 26 de febrero de 2002, párrafos 39 y 40. En su símil interamericano, la CIDH, Olmedo Bustos y otros v. Chile, sentencia de 5 febrero 2005; y CIDH, Kimel v. Argentina, sentencia de 2 de mayo 2008. Palermo (2010) p. 278.
} 
La comprensión americana está ligada a los primeros desarrollos de la privacidad, que fueron realizados dentro de la tradición anglosajona, al alero del derecho de propiedad, que lo conceptualiza como un espacio o ámbito de acción privilegiado y exento interferencias, un espacio "privado", especialmente opuesto a lo público, un lugar donde podemos ejercer nuestro derecho a ser dejados solos ${ }^{39}$.

Sin embargo, la privacidad ha visto también un desarrollo diferente y más amplio en el espacio europeo, construida más sobre la idea de dignidad humana que de propiedad, que se vincula con el derecho al libre desarrollo de las formas de vida y con la protección del derecho de toda persona a vivir como dueña y arquitecta de su propio destino. Ello permite excluir del dominio público ciertas informaciones que estigmatizan al afectado, o que limitan o perjudican el ejercicio pleno de este derecho ${ }^{40}$. Proteger la autonomía y la libertad individual supone la protección del sujeto con sus características distintivas actuales, en correspondencia con su imagen pública ${ }^{41}$. El reciente fallo del TJUE sobre el caso Google será un importante refuerzo a esta postura.

\section{El OBJETIVO RESOCIALIZADOR DE LA PENA COMO JUSTIFICACIÓN DEL DERECHO AL OLVIDO}

La faceta más clásica del derecho al olvido está relacionada con el pasado judicial de un individuo, especialmente en materia penal y comercial, y en Europa ha tenido una amplia y creciente aceptación ${ }^{42}$.

Si partimos de la base que la reinserción y rehabilitación del infractor son objetivos propios de la punición estatal, la publicidad y reiteración ad aeternum de los hechos delictuales y las condenas recaídas sobre ellos podría resultar claramente perjudicial para el

39 Esta expresión fue popularizada por el célebre artículo sobre "Privacidad” de Warren y BrandeIs, quizá el más influyente a nivel mundial sobre el tema. WARREN y BRANDEIS (1890). En el mismo sentido se pronuncia Miller, quien literalmente dice que "el derecho a la privacidad se presenta como el derecho de estar solo y ahora debe considerarse desde la perspectiva de la "habilidad individual para controlar la circulación de información relativa a él mismo..." Miller (1971).

Por su parte, el TCE ha señalado en su STC 134/1999, FJ 5 que "El art. 18.1 no garantiza una "intimidad" determinada, sino el derecho a poseerla, a tener vida privada, disponiendo de un poder de control sobre la publicidad de la información relativa a la persona y su familia, con independencia del contenido de aquello que se desea mantener al abrigo del conocimiento público. Lo que el art. 18.1 garantiza es un derecho al secreto, a ser desconocido, a que los demás no sepan qué somos o lo que hacemos, vedando que terceros sean particulares o poderes públicos, decidan cuáles sean los lindes de nuestra vida privada, pudiendo cada persona reservarse un espacio resguardado de la curiosidad ajena, sea cual sea lo contenido en ese espacio. Del precepto constitucional se deduce que el derecho a la intimidad garantiza al individuo un poder jurídico sobre la información relativa a su persona o a la de su familia, pudiendo imponer a terceros su voluntad de no dar a conocer dicha información o prohibiendo su difusión no consentida”. En el mismo sentido se pronuncian las STC 144/1999, STC $115 / 2000$, STC 185/2000 y STC 127/2003, entre otras.

40 Rolla señala que esta profunda evolución "supera, en primer lugar, una concepción de la privacy estrechamente vinculada al derecho de propiedad”. Rolla (2002) pp. 150-151. En un sentido similar, Rodotá (2005) p. 228.

41 Mezzanotte (2009) pp. 69-70, 79 y 81.

42 Costaz (1995) pp. 961 y ss.; Letteron (1996) pp. 388 y ss.; y Strowel (1998) pp. 126 y ss. Siguiendo este criterio, la Directiva 95/46 Art. 8,\$5, recomienda una protección más alta para la información sensible, como por ejemplo las condenas penales e infraccionales, a las que pueden agregarse incluso algunas de carácter civil o administrativo. 
adecuado desarrollo futuro de quienes se han equivocado (criminalización secundaria) ${ }^{43}$, justificando la restricción de dicha publicidad ${ }^{44}$.

En el constitucionalismo moderno, este objetivo de la pena ha sido especialmente valorado, por lo que podría sostenerse que incluso en aquellos ordenamientos donde no se encuentra expresamente señalado, podría formar parte del "contenido constitucional implícito", y bajo esa fórmula debería ser igualmente respetado ${ }^{45}$.

En el contexto europeo, existe abundante material jurisprudencial que se pronuncia en este sentido.

Por ejemplo, en el caso $A$. v. Noruega ${ }^{46}$, el TEDH señaló que la forma en que la noticia había sido presentada, podía hacer parecer al afectado como sospechoso del crimen, utilizando el criterio de un "lector ordinario" en el ejercicio de ponderación correspondiente ${ }^{47}$. La Corte de Estrasburgo también consideró que el acoso periodístico y las referencias realizadas afectaban su proceso de rehabilitación y reinserción social (el afectado debió abandonar su trabajo y su hogar), señalando que la conducta de los medios había sido ilegítima.

El TC alemán también ha utilizado criterios semejantes. Por ejemplo, en el caso Lebach $^{48}$, un condenado a punto de salir en libertad solicitó y recibió protección contra la emisión de un programa televisivo en que se haría referencia a su caso, a su imagen y a sus tendencias homosexuales, señalando que ello afectaba su reinserción ${ }^{49}$. La Corte de Casación italiana tuvo una postura idéntica frente a la supuesta participación de un sujeto en hechos de mafia, ampliamente publicitada 6 años atrás, y de los cuales había sido declarado inocente ${ }^{50}$.

En España, el TCE ha señalado que solo un interés noticiable muy cualificado puede legitimar la difusión de antecedentes penales de una persona al amparo del ejercicio del derecho de información ${ }^{51}$. Asimismo, el TS consideró que los antecedentes de una persona absuelta no están protegidos por la libertad de información ${ }^{52}$.

\footnotetext{
43 La publicidad permanente de las decisiones judiciales opera como una suerte de "pena complementaria perpetua”. LeSUEUR DE GIVRY (2001)

44 A nuestro entender, el derecho al olvido alcanza tanto a condenas realmente cumplidas como a las acciones prescritas. Para un mayor desarrollo, MezzanotTe (2009) p. 121.

45 En Italia, por ejemplo, la resocialización e reinserción del delincuente es un objetivo constitucional expresamente recogido por el artículo 27.3 de la Constitución.

46 CEDH No 28070/06, A. v. Noruega, de 9 de julio de 2009, originado por las alusiones realizadas por ciertos medios de comunicación a un testigo, previamente condenado a 16 años de prisión por homicidio, que lo identificaban como autor de un delito de violación y asesinato de dos menores, del que luego fue declarado inocente.

47 Para ello, entre otros factores, el TEDH consideró la Recomendación 13 (2003) (principio 8) sobre divulgación de información a través de los medios de comunicación respecto a procedimientos, que señala: "La divulgación de información sobre personas sospechosas, acusadas o condenadas o sobre otras partes implicadas en procedimientos penales deberá respetar su derecho a la protección de la privacidad conforme al artículo 8 (RCL 1999, 1190-1) del Convenio".

48 BVerfGE 35, 2002, 1973.

49 Navarro (2011) p. 141 (nota 139).

50 Sentencia de la Corte de Casación Italiana, No 3679, de 9 de abril de 1998

51 STC 52/2002, se estimó que la publicidad mediática dada a los antecedentes penales de una persona por una violación acaecida hace doce años, y por un arresto menor, eran superfluas e innecesarias, dado que la noticia fundamental se había centrado en descartar su participación en el doble crimen (homicidio). Añadir aquellas referencias, que afectan a su probidad, reputación y dignidad personal, era innecesario. La Audiencia Provincial y el Juzgado de Primera Instancia sostenían lo contrario.

52 STS de 16 de enero de 1986.
} 
En el caso llamado "Crimen de la Rivera", la afectada alegó que la vinculación realizada por la prensa os periódicos entre un proceso penal actual y otro antiguo de la que ella fue víctima (inducción a la prostitución, cuando ella tenía 14 años), vulneraba su derecho al honor "al vincularla a una actividad socialmente reprobada, que proyecta sobre su persona un juicio negativo, agravándose tal vulneración al publicarse detalles, innecesarios e irrelevantes para el interés público propio de la información sobre la muerte que se imputó al padre de la recurrente, y que constituía la noticia principal, tales como haber estado enamorada de uno de los inductores a la prostitución y el precio de los servicios sexuales prestados, que confieren a la noticia un matiz injurioso, denigrante, desproporcionado y morboso (...) aunque no se hubiese publicado su nombre y apellidos ni divulgado su imagen, resultaba perfectamente identificable a partir de los datos proporcionados en las noticias combatidas -el nombre, los apellidos y las fotografías del padre y la edad de la hija-, así como la localización de los hechos, tratándose de una pequeña población de la provincia" 53 .

Sin embargo, Gómez Bermúdez y Beni Uzábal señalan que lo anterior dista mucho de constituir la regla general, ya que "ciertos tribunales consideran que el hecho de que el acusado haya sido condenado con anterioridad o su condición de personaje público, en el más amplio sentido del término, es suficiente para considerar que su imagen puede ser ofrecida a través de los medios sin menoscabar sus derechos, mientras que otros estiman que debe ser siempre consultado y su decisión respetada. En el punto intermedio se encuentran los casos en que el tribunal estima que la difusión pública de la imagen del acusado puede aumentar desproporcionadamente los perjuicios de someterse a un proceso... y establecen medidas restrictivas como la desfiguración del rostro y voz u otras similares" 54 .

En Italia, este criterio ha sido más fácilmente aceptado pues el artículo 27.3 de la Constitución se refiere al objetivo reeducativo y resocializador de la pena, el que debe vincularse con la necesidad de la misma de respetar la dignidad humana ${ }^{55}$.

Siguiendo esta línea, el Tribunal de Roma cuestionó en 1995 la publicación de ediciones anteriores de un periódico, con fines promocionales, incluyendo la confesión de un grave delito por parte de una persona (1961), que se individualizaba. Producto de la publicación, el afectado, que había cumplido su pena y recibido una medida de gracia, perdió su trabajo y fue objeto de desconfianza por su entorno, en circunstancias que la falta de interés actual de la noticia era evidente ${ }^{56}$.

Fundado en lo anterior, la Recomendación 13 (2003) del Consejo de Europa establece, en su principio número dieciocho, que los reportajes realizados por los medios de comunicación sobre el seguimiento de la ejecución de penas, con el fin de no causar un perjuicio a la reinserción en la sociedad de las personas que han cumplido una condena, deben respetar su derecho a la vida privada. Esto incluye el derecho a proteger su identidad en relación con el delito cometido anteriormente una vez que han cumplido su condena, salvo

\footnotetext{
53 STC 121/2002, FJ 2.

54 Gómez y Beniuzábal (2006) p. 270.

55 Por ello la prescripción está establecida sobre todo como garantía del individuo antes que del ordenamiento penal. Palermo (2010) p. 280.

56 Tribunal de Roma el 15 de mayo de 1995. Palermo (2010) p. 280.
} 
que consintieran explícitamente la divulgación de su identidad o cuando estas personas y el delito que cometieron se hubieran convertido en un asunto de interés público ${ }^{57}$.

Algo similar sucede con las normativas que desde hace décadas regulan los registros públicos de informaciones penales y comerciales. Asimismo, razones similares pueden encontrarse dentro de los efectos buscados por otras instituciones del derecho. Pese al uso abusivo que se ha hecho de la prescripción y la amnistía en diferentes circunstancias históricas, bien utilizadas pueden servir aumentar los niveles de seguridad y certeza, liberando a las relaciones sociales de un excesivo peso vinculado al pasado ${ }^{58}$.

\section{El DEBIDO PROCESO Y LA IMPARCIALIDAD DEL JUZGADOR COMO FUNDAMENTOS DEL DERECHO AL OLVIDO \\ El derecho a ser juzgado en un proceso con garantías, o derecho a un juicio justo o} debido proceso, depende de una serie de factores.

El más importante de ellos es la imparcialidad judicial, que tiene tanto una vertiente objetiva (ausencia real de vínculos y prejuicios relevantes por parte del juzgador frente a las partes e intereses en juego), como otra objetiva (que el juzgador pueda ser apreciado por la sociedad como un juez imparcial, de acuerdo a sus circunstancias).

La excesiva publicidad dada a ciertos antecedentes de una persona, podría afectar, al menos, a la imparcialidad entendida como "confianza" o "autoridad judicial". E incluso, se sostiene podría afectar al menos a aquellos jueces con menor preparación y experiencia, como por ejemplo, los jurados.

Por lo anterior, se permite tomar una serie de medidas que suponen la supresión, transitoria o permanente, de la posibilidad de recordar ciertos hechos frente a un proceso judicial en curso, especialmente cuando ellas obedecen a campañas mediáticas más o menos orquestadas (juicios paralelos) ${ }^{59}$.

La jurisprudencia relativa a esta materia es abundante. Una de las más conocidas corresponde a "Nebraska Press Assn. v. Stuart", donde se prohibió a la prensa difundir las confesiones anteriores de los acusados en un juicio por asesinato múltiple altamente publicitado, para proteger el desarrollo del juicio y la imparcialidad de los juzgadores ${ }^{60}$.

\section{LA PROTECCIÓN DE LAS VÍCTIMAS COMO FUNDAMENTO DEL DERECHO AL OLVIDO}

De más está mencionar el alto interés existente en que la víctima de un delito no se vea permanentemente asociada al ultraje que la ha afectado (victimización secundaria).

\footnotetext{
57 En el mismo sentido Narváez (2002) p. 50; y Otero (2000) p. 246. En contra, la STS de 30 de diciembre de 1989.

58 Para algunos autores solo la amnistía y la rehabilitación dan lugar al derecho al olvido como derecho subjetivo, más no la prescripción de la pena.MezzAnotTe (2009) p. 226 (cita No 66).

59 El TCE ha señalado que: "la Constitución brinda un cierto grado de protección frente a los juicios paralelos en los medios de comunicación” (STC 136/1999, FJ 8, utilizando una expresión que proviene del AC 195 de 1991, FJ 6). En el mismo sentido, entre otros, la STC 187/1999, FJ 10, y la Declaración del Pleno del CGPJ, de 25 de enero de 1995. Existe también abundante doctrina al respecto. Por ejemplo, Cortés BeChiarelli, (2003); Juanes Peces (2012); Orenes Ruiz (2008); Bravo (2012); Espín Templado (1990); Latorre, (2002); Rodríguez (2012); Quintero (1990); Valldecabres (2004); Roxin (1999); Apalategui y Marín (2012).

60 Nebraska Press Assn. v. Stuart, 427 U.S. 539 (1976).
} 
Frente a esta situación, el derecho al olvido tendrá una fundamentación especialmente fuerte. En EE.UU. la extensión dada a la libertad de expresión permite sostener un criterio opuesto, afectando incluso a víctimas de violación ${ }^{61}$.

\section{SITUACIONES RESISTENTES AL OLVIDO}

Finalmente, nos referiremos a las situaciones que pese a concurrir el requisito del paso del tiempo y afectar derechos protegidos, ofrecen resistencia al derecho al olvido.

Aceptando la premisa de que ningún derecho es ilimitado y siempre puede ceder ante otras necesidades e intereses, podemos utilizar como principio general que la especial protección que ofrece la libertad de expresión e información va asociada primeramente a la trascendencia pública de los hechos divulgados, la que dependerá de la relevancia de la materia, su interés público y su capacidad para contribuir a la formación de una opinión pública libre ${ }^{62}$.

Ante la falta de necesidad social de transmitir cierta información, los hechos vuelvan a quedar bajo control de las personas y por lo mismo, protegidas por su derecho a la privacidad $^{63}$.

Sin embargo, este principio puede presentar algunas matizaciones.

1. Dinamismo en la dimensión del interés público de un hecho del pasado. Puede suceder que algunas circunstancias vuelvan actual la información pasada, como cuando la primera publicación y la posterior hubieren sucedido hechos que fueran capaces de volverles su carácter de actualidad (acá comprendemos al interés público informativo como un elemento dinámico).

Así pudo observarse, por ejemplo, en el caso Time, Inc. v. Hill, en que la historia de una familia que fue tomada rehén por un grupo de delincuentes prófugos, fue llevada a una novela, y posteriormente, a un exitoso musical en Broadway, haciendo renacer, en buena medida, el interés del público sobre el caso ${ }^{64}$. Este tipo de situaciones nos muestran que el solo paso del tiempo no permitirá inclinar la balanza a favor del olvido, volviendo necesario el ejercicio de balanceo.

${ }_{61}$ Cox Broadcasting Corp. v. Cohn, 420 U.S. 469 (1975). Florida Star v. B. J. F., 491 U.S. 524 (1989).

62 STC 49/2001, FJ 6; y STC 121/2002, FJ 3.

63 Para Rolla, "el decálogo al que sería preciso atenerse para que el derecho a la información no lesione el derecho a la vida privada puede encontrarse en la sentencia 5259/84 de la Corte de Casación, de acuerdo con la cual una información sería respetuosa con el derecho a la personal reserva cuando satisfaga los siguientes criterios: utilidad social de la información; verdad objetiva, incluyendo también en tal noción la veracidad o verdad putativa, fruto de un diligente y serio trabajo de contraste; forma adecuada de exposición y valoración de los hechos, excluida toda intención denigratoria”. Rolla (2002) p. 165. La sentencia 3679/98, señaló que el derecho al olvido era menor si el hecho mismo ya había sido objeto de un gran interés público en el momento en que sucedió (pasado), y por lo mismo o por otra razón, pudiese subsistir un interés público en la noticia, siendo ilegítimos cualquier actividad privada o incluso pública sin relación con los hechos judiciales, o que solo se vincularan con la vida privada de la persona involucrada en los hechos investigados y conocidos. Mezzanotte (2009) p. 121.

${ }^{64}$ Time, Inc. v. Hill, 385 U.S. 374 (1967). Dado que la renovación del interés público puede ser generada en forma interesada y con ánimo lesivo, es necesario analizar la posibilidad de crearse salvaguardas legales en este sentido. 
2. Necesidad de conservar determinados antecedentes. La pérdida de interés público sobre un hecho rara vez permitirá la eliminación completa de antecedentes ${ }^{65}$, ya que ellos pueden tener un gran interés y utilidad para otros asuntos diferentes. Un buen ejemplo de este interés sería la investigación científica o histórica ${ }^{66}$ o el pasado de figuras de relevancia política y social ${ }^{67}$, pues en estos casos la pérdida de los antecedentes podría provocar daños irreparables u operar como censura.

Siguiendo este criterio, el Proyecto de Reglamento para el Tratamiento de Datos Personales señala en su artículo 17 No 3 que la supresión de datos personales no procederá cuando ellos sean necesarios para el ejercicio del derecho a la libertad de expresión, para realizar un interés público vinculado al ámbito de la salud, o sean necesarios para la investigación histórica, estadística y científica o el cumplimiento de una obligación legal.

Así se conserva el principio general que garantiza la posibilidad de informar ampliamente sobre asuntos de interés público actual puede compatibilizarse, con la necesidad de dejar excluidas de protección a "todas aquellas informaciones del pasado publicadas en ausencia de un interés social, especialmente cuando tuvieran la capacidad de alterar la imagen externa y social de una persona" ${ }^{38}$.

3. Necesidades de seguridad pública. El objetivo de la reinserción y resocialización de quien ha cometido un delito, que sirve de base a una de las más clásicas versiones del derecho al olvido, también puede chocar con otros intereses jurídicos relevantes, obligándonos a un nuevo ejercicio de ponderación. El discutible objetivo de prevención general de la pena, las políticas y prácticas de seguridad y la exigencia de publicidad del proceso, por ejemplo, obligan a dar publicidad a cierta información judicial.

Especialmente crítica parece la existencia de registros públicos de infractores con antecedentes penales, o incluso comerciales (deudas, etc.), muchas veces fundado en "necesidades de seguridad pública".

El mayor desarrollo de este tipo de registros ha sido observado en EE.UU. ${ }^{69}$, donde su constitucionalidad fue expresamente validada, incluso cuando ello implicaba dar

\footnotetext{
65 REDiNG (2012) señaló que el borrado de datos no sería total ("cannot amount to a right of the total erasure of history") y se referiría principalmente a la que haya sido entregada por una persona.

66 El TCE ha señalado que los hechos históricos pueden permitir incluso una protección mayor que el garantizado por la libertad de expresión e información. De hecho, este criterio fue aplicado en la STC 43/2004. De especial interés sobre esta materia resulta el FJ 5.

${ }^{67} \mathrm{CEDH}$ No 13704/88, Schwabe v. Austria, de 28 de agosto de 1992, párrafos 32 y 34 . El cumplimiento de la condena no limita, en estos casos, el derecho de la comunidad a recordarlo y hacerlo presente.

68 Rolla (2002) p. 153.

69 Desde 1994, EE.UU. ha sido pionero en este tipo de registros. La norma más importante es la Megan's Law de New Jersey, y muchas leyes similares reciben su nombre (Megan es el nombre de una niña asesinada por un condenado por delitos sexuales).
} 
acceso a la prensa y publicidad a las víctimas de delitos sexuales ${ }^{70}$, y pueden ser fácilmente consultados, incluso por internet ${ }^{71}$.

Estos registros no solo resultan cuestionables desde el punto de vista de la dignidad personal, el objetivo resocializador de la pena y su utilidad para prevenir futuros delitos, sino que habitualmente afectan otros derechos constitucionales específicos, como la no retroactividad de la ley (ex post facto, que en este caso cambia a posteriori los efectos jurídicos vinculados a la comisión de un delito, agravando la pena) y el debido proceso legal (due process of law) ${ }^{72}$, así como la igualdad ante la ley, al exponer solo a un grupo dentro de un grupo de personas que estaban en idéntica condición: los condenados $^{73}$. Por ello, incluso allí donde son permitidos, incorporan normas sobre prescripción de delitos y cancelación de antecedentes penales, civiles y comerciales.

Cabe señalar que uno de los principales objetivos de la alta protección generalmente dada a la crónica judicial tiene por objeto permitir a la opinión pública el conocimiento y escrutinio del sistema penal y las actuaciones de sus tribunales, así como de los hechos delictivos, por lo que es posible considerar restricciones referidas a los nombres de los involucrados sin afectar estos objetivos.

Sin embargo, la jurisprudencia norteamericana nuevamente marca una nota discordante en esta materia, al señalar que cada elemento de la noticia es relevante, rechazando los reclamos fundados en la falta de necesidad de que un nombre hubiese sido revelado ${ }^{74}$.

Asimismo, se protege la publicación de la historia criminal, como lo muestra la firme actitud de Wikipedia frente al reclamo de los dos ciudadanos alemanes condenados por el asesinato de un famoso actor, y que son mencionados en la página del mismo ${ }^{75}$. Pero más allá de este criterio, podemos encontrar ciertas señales de apertura que sostienen, por ejemplo, que los avances técnicos han cambiado radicalmente el equi-

70 Cox Broadcasting Corp. v. Cohn, 420 U.S. 469 (1975). En España se levantó cierta polémica en torno a la supuesta decisión adoptada por las cortes de Castilla la Mancha de crear un fichero o listado de Maltratadores de Género, aunque ella en realidad solo consistió en permitir la publicidad de sentencias firmes condenatorias sobre violencia doméstica con el consentimiento de la víctima o de las personas afectadas. ORENES (2008) p. 66.

${ }^{71}$ Ver, por todos, el catálogo disponible en la página web del FBI, disponible en http://www.fbi.gov/scamssafety/registry (consulta: 10 de mayo de 2014).

72 La tensión entre la existencia de estos registros y los derechos señalados se hizo evidente en el caso Smith $v$. Doe, 538 EE.UU. 84 (2003), que cuestionaba la pretensión de retroactividad de la Ley de Registro de Delincuentes Sexuales de Alaska y su carácter punitivo. El TSA señaló, en un fallo dividido (6-3), que la difusión no era lo suficientemente relevante como para considerarse una pena y que salvo fuertes pruebas en contrario, debía estarse a la intención declarada del legislador, que en este caso señalaba que el objetivo principal del registro era de protección de la comunidad. Agregó que el registro no se fundamentaba en la peligrosidad del sujeto (no era derecho penal de autor) sino en el antecedente objetivo y público de una condena previa, y que por lo mismo, no podía ser objeto de restricción. Ver también Smith v. Doe, 133, S. Ct, 1343-1345 (2003); y Doe I v. Otte, 259 F3d 979 (9th circ.2001)

73 Smith v. Doe, 538 EE.UU. 84 (2003), opiniones concurrentes.

74 Uranga v. Federal Publication Inc, Idaho, Supreme Court No 27118 (14 de febrero de 2003).

75 http://en.wikipedia.org/wiki/Walter_Sedlmayr. Rosen (2012) reenvía a John SchWARTz, "Two German Killers Demanding Anonymity Sue Wikipedia's Parent", N.Y. Times, nov. 12, 2009, at A13. 
librio alcanzado entre la necesidad de divulgar la información judicial y el derecho individual a ser olvidado ${ }^{76}$.

4. La publicidad de las actuaciones judiciales. Existe pleno consenso sobre la importancia de la publicidad procesal, frente a las partes y frente a terceros, así como sobre la necesidad de garantizar un pronunciamiento público de la sentencia ${ }^{77}$.

Las razones que justifican la publicidad de las actuaciones judiciales como una situación de libertad de información especialmente protegida, se fundan en la necesidad de contar con una opinión pública informada sobre la actividad de los tribunales y el funcionamiento del sistema jurídico, de manera tal que pueda escrutar, opinar, cuestionar sobre uno de los órganos más críticamente poderosos del Estado. Asimismo, la confianza en la justicia (imparcialidad de los tribunales, imperio del derecho, respeto del debido proceso, etc.) dependerá también de esta publicidad y constituye el mejor aliciente para el autocontrol y buen desempeño judicial (control social).

Sin embargo, debe distinguirse entre publicidad de las actuaciones procesales de la publicación más o menos masiva de las mismas. De hecho, ambas obedecen a objetivos diferentes, lo que queda en evidencia por el hecho de que la mayoría de las sentencias no son objeto de publicidad mediática alguna. La publicidad del proceso y de la sentencia podría perder valor y ceder frente a otros derechos una vez que los objetivos que se buscaban hayan sido satisfechos, lo que típicamente ocurrirá con el transcurso del tiempo.

En este esquema, se podrán impetrar una serie de medidas, de distinta graduación según las circunstancias del caso, y que podrán ir desde la prohibición de reproducir los nombres y demás señas características de los condenados rehabilitados (fotografías, etc.), hasta la prohibición absoluta de divulgar ciertos antecedentes carentes de interés público, siempre dentro del encuadre de un juicio de ponderación o balanceo circunstanciado (la cercanía de un proceso ante jurados que afecte a la misma persona, etc.).

Finalmente, hay otro tipo de publicidad de las actuaciones judiciales, y en especial de las sentencias, que precisa de otro nivel de información y que por su propia naturaleza puede ser objeto de un tratamiento diferente: el estudio del derecho por medio de la jurisprudencia por parte de investigadores y operadores jurídicos (abogados, historiadores, etc.) y que enfrenta igualmente importantes desafíos ${ }^{78}$.

En efecto, el reciente acceso a la jurisprudencia mediante bases de datos electrónicas ha permitido aumentar significativamente la cantidad y disponibilidad de las mismas, facilitando su uso impropio: selección laboral, concesión de créditos comerciales, periodismo de entretención (carente de interés público), etc. ${ }^{79}$. Esta situación

\footnotetext{
76 United States Department of Justice v. Reporters Committee for Freedom of the Press, 489 U.S. 749 (1989).

77 Ver, por todas, el artículo 6 de la Convención Europea de Derechos Humanos.

78 Seguiremos en este punto el desarrollo realizado por DE TERWAGNe (2005).

79 La accesibilidad de la jurisprudencia está generando riesgos y desafíos que nunca habían estado presentes en la historia jurídica.
} 
ha sido bien advertida por numerosas instancias europeas ${ }^{80}$, generando diversas propuestas de regulación.

La Directiva 95/46, referida a esta materia, ha señalado que los datos a publicar deben ser pertinentes, adecuados y no excesivos de acuerdo a las finalidades perseguidas $^{81}$, y que toda publicidad realizada sin atender realmente al fin legítimo que la autoriza, está prohibida ${ }^{82}$.

Dentro de esta lógica, la necesidad y relevancia de la publicación de información personal para el conocimiento y estudio de la jurisprudencia dentro de un sistema jurídico es más que cuestionable. A diferencia de lo que ocurre con jueces e incluso con los abogados, rara vez el nombre de las partes y testigos será un aporte para la comprensión de la justicia y su funcionamiento, o para el control de las actuaciones jurisdiccionales, por lo que pueden gozar de niveles más elevados de protección ${ }^{83}$. Muchos países han avanzado en este sentido, permitiendo esta publicidad solo para fines de de "documentación, estudio y de investigación en el campo jurídico" 84 .

Por otro lado, en los países que forman la Comunidad Europea existe un amplio consenso respecto al uso del anonimato sin petición de parte como regla general en la publicidad masiva dada a las actuaciones judiciales ${ }^{85}$. Alemania, Austria, Bélgica, España, Finlandia, Francia, Grecia, Hungría, Holanda, Polonia, Portugal y la República Checa utilizan este criterio y Dinamarca, Italia, Suecia y el TJUE utilizan un anonimato parcial de primera instancia. Solo Reino Unido se mantiene aferrado a la tradición de dar plena publicidad a los nombres de los involucrados ${ }^{86}$.

Cabe señalar que ninguno de estos países ha dejado de utilizar los datos completos para dar pronunciamiento público de la sentencia, y lo mismo ocurre con el material que se conserva en los archivos judiciales y que son accesibles a público. El anonimato solo se aplica a la publicación masiva ${ }^{87}$.

80 De Terwagne (consulta: 9 de mayo de 2014). Ella se refiere a una serie de documentos que ya no se encuentran disponibles en internet. (Groupedeprotectiondespersonnesàl'égarddutraitementdesdonnéesàcaractèrepersonnel,avis3/99 du 3mai1999concernantl'informationémanantdusecteurpublicetlaprotectiondesdonnéesàcaractère personnel, p. 7, http://europa.eu.int/comm/internal_market/eu/media/dataprot/wpdocs/wp20/fr.pdf de 2001 CNIL, Délibération 01-057 du 29 novembre, Avis07/98,disponible à l'adresse www.privacy.fgov.be)

81 Art. 4\$ 1er, c).

82 Art. 6,\$ 1er b).

83 Por ello, pueden ser publicados, pero en forma no excesiva, de acuerdo al principio de proporcionalidad, por ejemplo limitando su publicidad al formato papel o en bases electrónicas no indexables, solo por un tiempo, por decisión fundada del tribunal, etc.), de acuerdo al verdadero interés de su publicación.

84 Autorización No 7 de 2002 del Garante per la protezione dei dati personali italiano, sobre los datos personales de naturaleza judicial. La Recomendación R (95) 11 del Consejo de Europa, de 11 de septiembre de 1995 señala criterios que van en la misma dirección.

85 Desgraciadamente, no se han regulado las bases de datos privadas.

86 Toda esta información, al igual que mucha de la utilizada en esta sección, ha sido tomada de DETERWAGNE (2005).

87 La CNIL francesa, incluso ha señalado que el riesgo de la pérdida de control sobre la información, sumado a los riesgos del abuso de las finalidades para la publicación son de tal magnitud, que la única manera de garantizar una adecuada protección de los derechos es consiguiendo el consentimiento expreso de los involucrados. 


\section{CONCLUSIONES}

El derecho al olvido, como categoría autónoma, es reciente y cuenta con un desarrollo doctrinario y jurisprudencial aún precario, lo que no ha sido obstáculo para que en diversos foros se haya propiciado su reconocimiento, incluso a nivel normativo.

El objetivo detrás de este reconocimiento es el de favorecer la posibilidad de toda persona a construir su vida sin el peso del pasado, considerando que muchas veces no se reporta una utilidad social que justifique las consecuencias negativas asociadas a la publicidad de un hecho, sobre todo cuando el paso del tiempo ha mermado el interés público que alguna vez recayó sobre el mismo.

Lo anterior no es otra cosa que el resultado de enfrentar un conflicto entre derechos protegidos con la lógica de la ponderación.

A las situaciones clásicamente vinculadas a este derecho, como el objeto resocializador de las sanciones penales, la protección de la imparcialidad del juez y de la identidad de las víctimas, la protección de la privacidad frente a la publicidad de hechos sin interés público, entre otras, en las últimas décadas se ha agregado de manera desequilibrante una problemática asociada a los nuevos desarrollos tecnológicos y al mundo de internet, transformando esta problemática en un asunto masivo y cambiando las estrategias para abordarlo. No obstante, en estos desarrollos más tardíos se han incorporado situaciones que merecen protección e intervención jurídica, pero donde el factor temporal propio del derecho al olvido está ausente (borrado de datos, rectificación de información, etc).

Los problemas jurídicos asociados al olvido y la memoria pública de hechos del pasado pueden abordarse perfectamente como problemas de conflicto de derechos fundamentales, y más concretamente, como situaciones que justifican limitaciones legítimas al ejercicio de la libertad de expresión e información.

Sin embargo, hay buenas razones para intentar una regulación más estricta de estas materias, que ofrezca mayor claridad y predictibilidad y simplifique el trabajo del juez, especialmente frente a situaciones que pueden presentar un carácter típico y masivo, que requiera medidas tomadas con gran rapidez e incluso en forma preventiva. Este abordaje, empero, no deben llevarnos a olvidar que el núcleo del mismo es de naturaleza ius fundamental, base desde la cual deberán integrarse y complementarse los sucesivos desarrollos normativos que se planteen, así como las lecturas y soluciones que se adopten en sede judicial.

A nivel global, pese a las claras y marcadas diferencias entre la tradición americana y europea frente a esta materia -más proclive la primera a reforzar la libertad de expresión, mientras la segunda busca compatibilizarla con el derecho al olvido-, parece apreciarse la incorporación de elementos vinculados al factor temporal como límites a la libertad de expresión o información. Por ello, debemos suponer que en los próximos años seremos testigos de numerosos diálogos y propuestas en este sentido.

Cualquier medida que se adopte para enfrentar el derecho al olvido será polémica y deberá contemplar múltiples matices y situaciones particulares, debiendo además ser adaptada a los continuos cambios tecnológicos. Pero estas dificultades no deben llevar a la inacción ni legislativa ni judicial, so riesgo de negar protección a una serie de bienes jurídicos valiosos y aumentar la insatisfacción frente al derecho y a las posibilidades que ofrecen los nuevos adelantos tecnológicos. 


\section{BIBLIOGRAFÍA CITADA}

Aldunate Lizana, Eduardo (2010): "Aproximación Conceptual y Crítica al Neoconstitucionalismo", Revista de Derecho de Valdivia vol. 23, No 1: pp. 79-102.

Apalategui Isasa, Pedro y Marín, Manuel (2012): La Presunción de Inocencia y los Juicios Paralelos (Madrid, Editorial La Ley).

Auloos, Jef (2012): "The Right to Be Forgotten - Worth Remembering?" Forthcoming Computer Law and Security Review, vol. 28, Issue 2: pp. 3-17.

Bennett, Steven (2012): "The Right to Be Forgotten: Reconciling EU and US Perspectives", Berkeley Journal of International Law, vol. 30, Issue 1: pp. 161-195.

Bernal Pulido, Carlos (2007): "Refutación y Defensa del Neoconstitucionalismo", en Miguel Carbonell (edit.), Teoría del Neoconstitucionalismo (Madrid. Trotta) pp. 289-326.

Bravo, Gabriela (2012): "Derecho a la Información y Populismo Mediático", en Ovejero, Ana María (Coord.), La Presunción de Inocencia y los Juicios Paralelos (Madrid, Editorial La Ley)

Comanducci, Paolo (2002): "Formas de (Neo) Constitucionalismo: Un Análisis Metateórico”, Isonomía No 16: pp. 89-112.

Cortés Bechiarelli, Emilio (2003): "Juicios Paralelos y Derechos Fundamentales del Justiciable", Anuario de la Facultad de Derecho, No 21: pp. 123-151.

Covarrubias Cuevas, Ignacio (2005): "Notas Críticas a la Figura del Personaje Público como Criterio Legitimador para la Intromisión en la Vida Privada de las Personas", Revista del Centro de Estudios Constitucionales, vol. 3, No 2: pp. 163-197.

Covarrubias Cuevas, Ignacio (2013): La vida privada de las figuras pública: El interés público como argumento que legitima la intromisión en la vida privada (Santiago, LegalPublishing, Thomson Reuters)

CozTAz, Catherine (1995): "Ledroitàl'oubli", Gazette du Palais : pp. 961 y ss.

De Domingo, Tomás (2006): "El Problema de la Eficacia Horizontal de los Derechos Fundamentales", Revista de la Facultad de Ciencias Sociales y Jurídicas de ELCHE, vol. 1, No 1: pp. 291-301.

De Domingo, Tomás y Martínez-Pujalte, Antonio Luis (2011): "La Drittwirkung de los Derechos Fundamentales: Una Alternativa al Conflictivismo", Los Derechos Fundamentales en el Sistema Constitucional. Teoría General e Implicaciones Prácticas (Lima, Palestra Editores) pp. 134-162.

De Terwagne, Cécile (2005): "Diffusion de la Jurisprudence Via Internet dans les Pays de l'Union Européenne et Règles Applicables aux Données Personnelles”. Disponible en: http://www.crid.be/pdf/public/5021.pdf. Fecha de consulta: 9 de mayo de 2014).

Espín Templado, Eduardo (1990): "En Torno a los Llamados Juicios Paralelos y la Filtración de Noticias Judiciales", Revista del Poder Judicial, No Extra 13 sobre Libertad de Expresión y Medios de Comunicación: pp. 123-130.

Fioravanti, Maurizio (1996): Los Derechos Fundamentales: Apuntes de Historia de las Constituciones (Madrid, Trotta)

FLEISHER, Peter (2012): “The right of the forgotten”. Disponible en: http://www.peterfleischer.blogspot.com/2012/01/right-to-be-forgotten-or-how-to-edit.html Fecha de consulta: 10 de mayo de 2014 
Friedmann, Lawrence M. (1990): “The Republic of Choice: Law, Authority, and Culture”, The American Political Science Review, vol. 84, No. 4: pp. 1382-1384.

Gómez Bermúdez, Javier y Beni Uzábaql, Elisa (2006): Levantando el Velo. Manual de Periodismo Judicial (Madrid, Editorial Dossat).

GuAstini, Riccardo (2010): Teoría e Ideología de la Interpretación Constitucional (Madrid, Trotta).

Juanes Peces, Ángel (2012): “Independencia Judicial y Medios de Comunicación”, en Ovejero, Ana María (Coord.) La Presunción de Inocencia y los Juicios Paralelos (Madrid, Editorial La Ley).

Koops, Bert-Jaap (2011): "Forgetting Footprints, Shunning Shadows: A Critical Analysis of the "Rigth to Be Forgotten" in Big Data Practice", Tilburg Law School Research Paper, vol. 8, No 3: pp. 229-256.

Latorre Latorre, Virgilio (2002): Función Jurisdiccional y Juicios Paralelos (Madrid, Civitas).

Lesueur de Givry, Emmanuel (2001): "La question de l'anonymisation des décisions de Justice”. Disponible en : http://www.courdecassation.fr/rapport/rapport00/etudes\&doc/ LESUEUR.htm Fecha de consulta: 11 de mayo de 2014.

Letteron, Roseline (1996): Ledroitàl'oubli, Revue de Droit Publicet de la Science Politique, vol. 112, No 1-3.

Martínez Pujalte, Antonio Luis (1997): La Garantía del Contenido Esencial de los Derechos Fundamentales (Madrid, Centro de Estudios Políticos y Constitucionales).

Mezzanotte, Massimiliano (2009): Il Diritto All'oblio. Contributo Allo Studio Della Privacy Storica (Teramo, Edizioni Scientifiche Italiane).

Miller, Arthur R. (1971): "The Assault on Privacy: Computers, Data Banks and Dossiers". Disponible en http://quod.lib.umich.edu/m/mqrarchive/act2080.0011.003?no de=act208.0011.003:19\&view=text\&seq=67 Fecha de consulta: 25 de mayo de 2014).

Narváez Rodríguez, Antonio (2002): "La Administración de Justicia y los Medios de Comunicación en una Sociedad Democrática”, Estudios Jurídicos del Ministerio Fiscal No IV: pp. 13-52.

Navarro Marchante, Vicente J. (2011): El Derecho a la Información Audiovisual de los Juicios (Madrid, Centro de Estudios Políticos y Constitucionales).

Orenes Ruiz, Juan Carlos (2008): Libertad de Información y Proceso Penal. Los límites (Navarra, Pamplona Aranzadi).

Orza Linares, Ramón M. (2012): "Derechos Fundamentales e Internet: Nuevos Problemas, Nuevos Retos", Revista de Derecho Constitucional Europeo, Año 9, No 18: pp: 275-336

Orza Linares, Ramón M. y Ruíz Tarrías, Susana (2011): "El Derecho al Olvido en Internet”. Disponible en: http://edcp.uoc.edu/symposia/wp-content/uploads/2011/06/Orza. pdf Fecha de consulta: 20 de mayo de 2014

Otero González, Pilar (2000): "Medios de Tutela ante los Juicios Paralelos durante la Fase del Juicio Oral”, Anuario de Derecho Penal y Ciencias Penales, vol. LIII, Fascículo 1: pp. 285-326. p. 246.

Palermo, Patrizia (2010): "Diffamazione e diritto all'oblio: equilibrio "elastico" tra tutela penale dell'onore e diritto di cronaca giudiziaria”, Rivista Penale, vol. 136, Fascículo 3: pp. 277 y 286. 
Pozzolo, Susanna (1998): "Neoconstitucionalismo y Especificidad de la Interpretación Constitucional", Doxa, No 21, vol. 2: pp. 339-353.

Prieto Sanchís, Luis (2003): “Neoconstitucionalismo y Ponderación Judicial”, en Miguel Carbonell (edit.), Neoconstitucionalismos (Madrid, Trotta) pp. 201-227.

Quinteros, Gonzalo (1990): "Libertad de Prensa y Protección de la Independencia e Imparcialidad Judicial", Revista del Poder Judicial, No Extraordinario 13 sobre Libertad de Expresión y Medios de Comunicación: pp. 335-360.

Reding, Viviane (2012): “The EU Data Protection Reform: Making Europe the Standard Setter for Modern Data Protection Rules in the Digital Age 5”. Disponible en: http:// europa.eu/rapid/pressReleasesAction.do? reference=SPEECH/12/26\&format=PDF Fecha de consulta: 11 de mayo de 2014.

Rodota, Stefano (2005): "La Pacifica Rivoluzione della Privacy", Questione Giustizia, No 2: pp. 228-243.

Rodríguez Ramos, Luís (2012): "La Actual Ficción del Secreto de las Actuaciones Sumariales como Conflicto de Derechos y de Poderes", en La Presunción de Inocencia y los Juicios Paralelos (Madrid, Editorial La Ley) pp. 145-152.

Rolla, Giancarlo (2002): "El Difícil Equilibrio entre el Derecho a la Información y la Tutela de la Dignidad y la Vida Privada. Breves Consideraciones a la Luz de la Experiencia Italiana”, Revista Mexicana de Derecho Constitucional, No 7: pp. 139-171.

Rosen, Jeffrey (2012): “The Right to Be Fortgotten” Disponible en: http://www.stanfordlawreview.org/online/privacy-paradox/right-to-be-forgotten?em_x=22 Fecha de consulta: 12 de mayo de 2014.

Roxin, Claus (1999): "El Proceso Penal y los Medios de Comunicación”, Revista del Poder Judicial, No 55: pp. 73-94.

SAmpere, Francisco Javier (2013 a): "Google, AEPD y Abanlex en el TJUE: otro punto de vista”. Disponible en: http://fjaviersempere.wordpress.com/2013/02/26/google-aepd-yabanlex-en-el-tjue-otro-punto-de-vista/ Fecha de consulta: 11 de mayo de 2014.

SAmpere, Francisco Javier (2013 b): “Caso "Google” sobre el derecho al olvido: ¿Cómo afecta a la propuesta de Reglamento de Protección de Datos?”. Disponible en http:// www.privacidadlogica.es/2013/06/25/caso-google-sobre-el-derecho-al-olvido-comoafecta-a-la-propuesta-de-reglamento-de-proteccion-de-datos/ Fecha de consulta: 13 de mayo de 2014.

Simón Castellano, Pere (2013): "El Carácter Relativo del Derecho al Olvido en la Red y su relación con otros Derechos, Garantías e Intereses Legítimos”, en Congreso Libertad, Transparencia y Politica en Internet: Ejercicio, Amenazas y Garantías (Madrid, Centro de Estudios Políticos y Constitucionales) Pendiente de publicación.

STrowel, Alain (1998): "Lesconditionsd' exercice du droitàl' oubli: liberté d 'informeret droitàl' oubli ”, Légipresse, No 154.

Valldecabres Ortiz, María Isabel (2004): Imparcialidad del Juez y Medios de Comunicación (Madrid, Tirant lo Blanch).

Warren Samuel D. y Brandeis, Louis D. (1890): “The Right to Privacy", Harvard Law Review, vol. IV, No 5: pp: 193-220 
Werro, Franz (2009): “The Right to Inform v. The Right to be Forgotten: A Transatlantic Clash”. Disponible en http://www.ssrn.com/abstract=1401357 Fecha de consulta: 8 de mayo de 2014).

Zárate, Sebastián (2013): "La Problemática entre el Derecho al Olvido y la Libertad de Prensa”, Revista Nueva Época, No 13: pp. 3 y 9.

\section{NORMAS CITADAS}

Reglamento General de Protección de Datos Personales de la Comisión Europea (2012b), artículo 17.

Resolución No R/02037/2012, A.A.A v. Agencia Estatal del Boletín Oficial del Estado, de fecha 29 de agosto de 2012.

Agencia Española de Protección de Datos, "Recomendaciones para una Navegación más Privada”.

Memoria de la Agencia Española de Protección de Datos, 2011.

\section{JURISPRUDENCIA CITADA}

Corte Europea de Derechos Humanos

CEDH No 28525/95, Unabhängige Initiative Informationsvielfalt v. Austria, de 26 de febrero de 2002.

CEDH No 13704/88, Schwabe v. Austria, de 28 de agosto de 1992.

Corte Interamericana de Derechos Humanos

Olmedo Bustos y otros v. Chile, sentencia de 5 febrero 2005.

Kimel v. Argentina, sentencia de 2 de mayo 2008.

Corte Europea de Justicia

Google Spain SL and Google Inc. v. Agencia Española de Protección de Datos (AEPD) and Mario Costeja González, Judgment of the Court (Grand Chamber) of 13 may 2014, Case C-131/12.

Corte Suprema de los Estados Unidos

Cox Broadcasting Corp. v. Cohn, 420 U.S. 469 (1975).

Florida Star v. B. J. F., 491 U.S. 524 (1989).

Nebraska Press Assn. v. Stuart, 427 U.S. 539 (1976).

Smith v. Doe, 538 U.S. 84 (2003).

Time, Inc. v. Hill, 385 U.S. 374 (1967).

US Dept. of Justice v. Reporters Committee, 489 U.S. 749 (1989).

Tribunal Constitucional Español

STC 6/1988

STC $144 / 1999$ 
STC 28/1996

STC $134 / 1999$

STC $136 / 1999$

STC $187 / 1999$

STC $115 / 2000$

STC $185 / 2000$

STC $290 / 2000$

STC 2/2001

STC $49 / 2001$

STC 52/2002

STC $121 / 2002$

STC $127 / 2003$

STC $158 / 2003$

STC $160 / 2003$

STC $43 / 2004$

STC 216/2006

\section{OTRAS SENTENCIAS}

ESPAÑA

STS de 16 de enero de 1986.

FRANCIA

Sentencia del Tribunal de Gran Instancia de Sena, 4 de octubre de 1965.

Sentencia del Tribunal de Gran Instancia de París, 6 de diciembre de 1979.

Sentencia de la Corte de Apelaciones de París, 15 de mayo de 1970.

Sentencia del Tribunal de Gran Instancia de París, Sala Primera, 25 de marzo de 1987.

Sentencia de la Corte de Casación, Sala Civil 2, de 3 de junio de 2004.

Sentencia de la Corte de Casación Civil del 20 de noviembre de 1990.

ITALIA

Sentencia de la Corte de Casación del 13 mayo de 1958, No 1563.

Sentencia de la Corte de Casación de 9 abril de 1998, No 3679.

Sentencia No 45051 de 24 de noviembre del 2009, dictada por la sección quinta de la Corte de Casación Penal Italiana.

Sentencia de la Corte de Casación Italiana, No 3679, de 9 de abril de 1998.

Pretura de Roma de 10 de febrero de 1988.

Alemania

BVerfGE 35, 2002, 1973. 
